Check for updates

Cite this: J. Mater. Chem. C, 2022, 10,3375

Received 1st November 2021 Accepted 27th January 2022

DOI: $10.1039 / d 1 t c 05263 b$

rsc.li/materials-c

\title{
Versatile methods for improving the mechanical properties of fullerene and non-fullerene bulk heterojunction layers to enable stretchable organic solar cells $\dagger$
}

\author{
Emilie Dauzon, (D) *a Xavier Sallenave, (DD ${ }^{\mathrm{b}}$ Cedric Plesse, ${ }^{\mathrm{b}}$ Fabrice Goubard, ${ }^{* \mathrm{~b}}$ \\ Aram Amassian (D)*c and Thomas D. Anthopoulos (D)*a
}

\begin{abstract}
We develop and evaluate two methods aimed at enhancing the mechanical resistance and stretchability of bulk heterojunction active layers in organic solar cells while maintaining photovoltaic performance intact. These techniques consist of adding a cross-linker or an elastomer into the active layer. First, we study P3HT:PC ${ }_{61} \mathrm{BM}$ blend as a reference polymer:fullerene acceptor system for our conceptual demonstration. The diazido cross-linker selectively reacts with $\mathrm{PC}_{61} \mathrm{BM}$ molecules and the resulting blend shows an overall softening effect of the mix, while the power conversion efficiency (PCE) increases by up to $20 \%$, which we attribute to increased aggregation of P3HT. Addition of elastomers affects the blend differently: the crystallinity of the donor decreases, which can have a detrimental effect on the PCE of certain materials. However, the elastomer method is found to be considerably more universal by acting as a mechanical softener in modern fullerene-free blend systems as well. In particular, SEBS elastomer displayed a tailored elasticity with various fullerene and non-fullerene blends: $\mathrm{P} 3 \mathrm{HT}: \mathrm{PC}_{61} \mathrm{BM}, \mathrm{PCE10}: \mathrm{PC}_{71} \mathrm{BM}$, and PCE13:IT-4F. The potential of our SEBS process is demonstrated in PCE13:IT-4F:SEBS solar cells with a PCE of $11.5 \%$. This versatile approach highlights the ease of manufacturing and scalability achieved by the solution casting processes, along with the high compatibility of acceptor and donor blends.
\end{abstract}

\section{Introduction}

Organic photovoltaic (OPV) devices have received much attention in the last two decades due to their promise of low-cost and environmentally friendly photovoltaics fabricated using scalable solution processing methods such as roll-to-roll manufacturing. Research in this area has mainly focused on improving the power conversion efficiency (PCE), which has recently approached $19.6 \%{ }^{1}$ Besides this promising performance, OPVs certainly offer other advantages such as portability, lightweight,

\footnotetext{
${ }^{a}$ King Abdullah University of Science and Technology (KAUST), KAUST Solar Centre, Thuwal 23955-6900, Saudi Arabia. E-mail: emilie.dauzon@kaust.edu.sa, thomas.anthopoulos@kaust.edu.sa

${ }^{b}$ Laboratoire de Physicochimie des Polymères et des Interfaces (LPPI), CY Paris Cergy Université, 95000 Cergy, France. E-mail: fabrice.goubard@cyu.fr

${ }^{c}$ Department of Materials Science and Engineering, and Organic and Carbon Electronics Laboratories (ORaCEL), North Carolina State University, Raleigh, N.C., 27695, USA. E-mail: aamassi@ncsu.edu

$\dagger$ Electronic supplementary information (ESI) available: Additional figures, TGA curve, FTIR spectra, optical microscopic images, visible-ultraviolet spectra, GIWAXS patterns, storage modulus, photovoltaic curves, stress-strain characterization, EQE. See DOI: 10.1039/d1tc05263b
}

and flexibility. One aspect of material design, which is rarely considered, but essential is mechanical compliance. Several other interesting potential applications require elasticity, like foldable smartphones, human skin, and wearable electronic textiles. ${ }^{2}$ Extensive work has also focused on stabilizing OPV materials and devices, a key step towards their commercial viability. ${ }^{3-9}$ In this regard, Krebs et al. found that one of the significant problems of OPV prototypes tested in the field was the fragility of OPV modules in the hands of children due to mechanical failure. ${ }^{5}$ Material and device stability along with good mechanical compliance and resistance to failure are therefore important to achieving long-term durability of OPV-based products. ${ }^{2}$ In contrast to the common opinion that organic materials are ductile, archetypal materials such as P3HT: $\mathrm{PC}_{61} \mathrm{BM}$ are stiff (Young's modulus: $2-3 \mathrm{GPa})^{10-13}$ and therefore not the most suitable for plastic electronics. Mechanical compliance and stretchability can be induced by applying architectural modifications to a device extrinsically, or intrinsically by manipulating material chemistry and blending. ${ }^{14-17}$ However, with the fast progress in the organic bulk heterojunction (BHJ) systems in terms of materials development, an adaptable method is now required to satisfy nonfullerene acceptor blends as well. To minimize costs and avoid 
the time-consuming and complexity associated with the chemical alteration of new polymers, the development of a general method applicable to achieve stretchability in a wide range of $\mathrm{BHJ}$ material systems would be particularly useful.

Cross-linking is a multipurpose tool to link molecules together by chemical bonds or bridges under a stimulus (ultraviolet irradiation or heat treatment). This strategy has been demonstrated to be a viable solution in OPVs for thermal and long-term stability. ${ }^{18-20}$ Furthermore, the three-dimensional network caused by cross-linking could provide opportunities to prevent mechanical failure and improve the overall elasticity. The benefit of cross-linking under strain has been demonstrated as an effective method. ${ }^{21-23}$ The decrease of the elastic modulus of 3,6-di-2-thienyl-pyrrolo[3,4-c]pyrrole-1,4-dione (DPP)based conjugated polymer using siloxane as a cross-linker was confirmed by Wang et al. ${ }^{21}$ While there are many studies on the modification of the BHJ polymer chemistry to enhance the deformation, ${ }^{13,14,24,25}$ less work has explored the effect of the cross-linkable molecule on the elasticity of $\mathrm{BHJ}$ blends. Derue et al. developed cross-linking molecules by click chemistry having two functional azides, 4,4'-bis(azidomethyl)-1,1'biphenyl (BABP), to limit the diffusion of $\mathrm{PC}_{61} \mathrm{BM}$ and hinder its crystallization. ${ }^{18,19,26}$

Another straightforward approach to enhance the stretchability is blending electronic materials with soft elastomers. Conjugated polymers dispersed in a stretchable matrix allow extreme mechanical deformations without compromising the electronic functionality. Materials embedded homogeneously in a rubber matrix have shown sufficient mechanical improvement to promote intrinsic stretchability of semiconductor polymers. For example, poly(3-hexylthiophene) (P3HT) blended with poly(dimethylsiloxane) (PDMS) leads to a stretchable material maintaining good charge mobility. ${ }^{27-29}$ Similarly, P3HT mixed with SEBS (Styrene Ethylene Butylene Styrene Block Copolymer) show high deformation. ${ }^{30}$ However, few reports demonstrate their mechanical benefits of blending in OPV devices. ${ }^{31,32}$

We investigate two different approaches to allow the photoactive $\mathrm{BHJ}$ layer to achieve mechanical compliance, namely the cross-linking or blending pathways. First, we investigate the effect of cross-linking on the elastic deformation of conjugated polymers. This is conceptually illustrated in Fig. 1a for a photoactive layer sandwiched between charge extracting layers and electrodes. In a first approach, we utilize three crosslinkable molecules (Fig. 1b) to tune the mechanical properties of the photoactive layer, namely 1,12-diazidododecane $\left(\mathrm{C}_{12} \mathrm{~N}_{3}\right)$, 1,11-diazido-3,6,9-trioxaundecane $\left(\mathrm{PEG}_{3} \mathrm{~N}_{3}\right)$, and poly(ethylene glycol)bisazide $\left(\mathrm{PEG}_{n} \mathrm{~N}_{3}\right)$. The chemistry of the cross-linker chains may play a role in the elasticity as suggested in some studies where organic polymers show a correlation between molecular weight and mechanical properties. ${ }^{33-35}$ Consequently, we decided to investigate different cross-linker chain natures: $\mathrm{C}_{12} \mathrm{~N}_{3}$ has a short non-polar chain, $\mathrm{PEG}_{3} \mathrm{~N}_{3}$ has a short polar chain, and $\mathrm{PEG}_{n} \mathrm{~N}_{3}$ is long and polar.

In a second approach, we utilize a physical blending approach whereby an elastomer is composited with the $\mathrm{BHJ}$

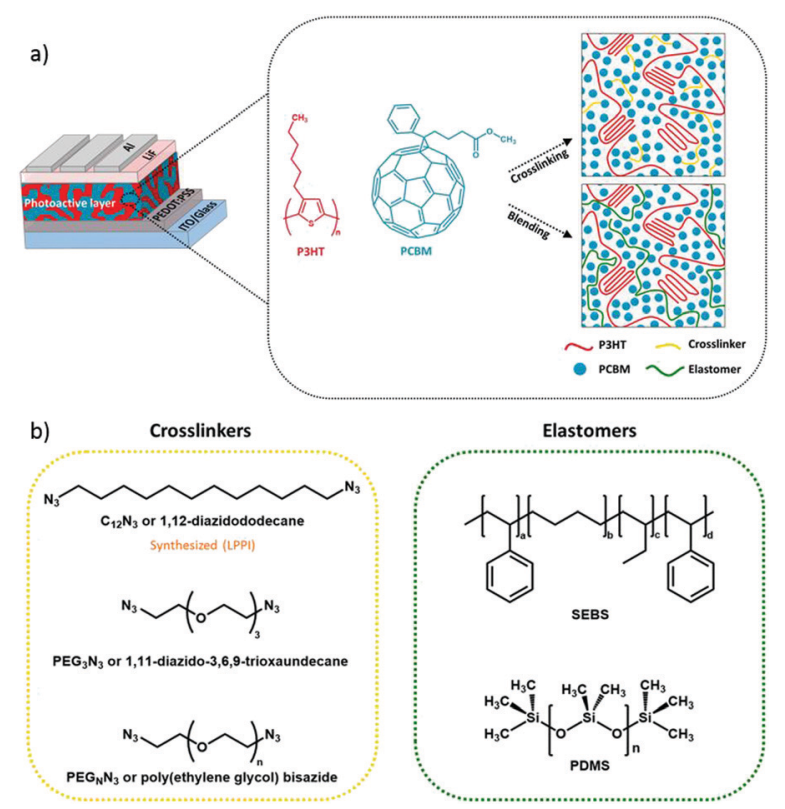

Fig. 1 (a) Illustration of the strategies to improve the mechanical reliability of blend solar cells via fullerene cross-linking or elastomer blending. (b) Chemical structures of the cross-linker molecules and elastomers.

as an effective approach to mechanically soften the photoactive layer. ${ }^{27,29,30,36,37}$ For the first time to our knowledge, we successfully implement elastomers as plasticizer components into photoactive $\mathrm{BHJ}$ layer of $\mathrm{OPV}$ devices. Unlike bis-azide molecules, which covalently bond to two $\mathrm{PC}_{61} \mathrm{BM}$ molecules, requires chemical specificity and treatment such as thermal annealing, the elastomer does not covalently bond with any $\mathrm{BHJ}$ component. Hence, this strategy can be extended in principle for thermally sensitive state-of-the-art non-fullerene OPV materials. We select a physical network, SEBS (Styrene Ethylene Butylene Styrene Block Copolymer) and a chemical network, PDMS (Polydimethylsiloxane) as elastomer components for this study (Fig. 1b). SEBS does not require heat treatment, which presents a major advantage over PDMS and cross-linkable molecules in solar cell fabrication. Heat-less method can increase the manufacturing speed and cuts the process complexity. Both of these strategies will be first evaluated on a reference $\mathrm{BHJ}$ photoactive layer consisting of $\mathrm{P} 3 \mathrm{HT}: \mathrm{PC}_{61} \mathrm{BM}$, then extended to more modern donor:acceptor blends where small-molecule acceptors other than fullerene are commonly employed.

\section{Experimental section}

\section{Materials}

Diazido-3,6,9-trioxaundecane $\left(\mathrm{PEG}_{3} \mathrm{~N}_{3}\right)$, poly(ethylene glycol) bisazide $\left(\mathrm{PEG}_{n} \mathrm{~N}_{3}\right)$, 1,12-dibromododecane, regioregular poly(3-hexylthiophene-2,5-diyl) (P3HT), [6,6]-phenyl- $\mathrm{C}_{61}$-butyric acid methyl ester $\left(\mathrm{PC}_{61} \mathrm{BM}\right)$ and $[6,6]$-phenyl- $\mathrm{C}_{71}$-butyric acid methyl ester $\left(\mathrm{PC}_{71} \mathrm{BM}\right)$ were purchased from Sigma. $\mathrm{PEG}_{n} \mathrm{~N}_{3}$ has a molecular weight (MW) of $1100 \mathrm{~g} \mathrm{~mol}^{-1}$, compared to $244 \mathrm{~g} \mathrm{~mol}^{-1}$ for $\mathrm{PEG}_{3} \mathrm{~N}_{3}$. PDMS was obtained from Dow Corning Sylgard 186. 
PEDOT:PSS low grade AI 4083 was purchased from Heraeus. Styrene ethylene butylene styrene block copolymer (SEBS) H1221 was purchased from Asahi Kasei. The following polymers were from Ossila: poly[4,8-bis(5-(2-ethylhexyl)thiophen-2yl)benzo[1,2- $\left.b ; 4,5-b^{\prime}\right]$ dithiophene-2,6-diyl-alt-(4-(2-ethylhexyl)-3fluorothieno[3,4- $b]$ thiophene)-2-carboxylate-2-6-diyl)] named PTB7-th or PCE10, 3,9-bis(2-methylene-((3-(1,1-dicyanomethylene)-6,7-difluoro)-indanone))-5,5,11,11-tetrakis(4-hexylphenyl)dithieno[2,3- $\left.d: 2^{\prime}, 3^{\prime}-d^{\prime}\right]-s$-indaceno[1,2- $\left.b: 5,6-b^{\prime}\right]$ di-thiophene (IT-4F), poly[(2,6-(4,8-bis(5-(2-ethylhexylthio)-4-fluorothiophen-2-yl)-benzo$\left[1,2-b: 4,5-b^{\prime}\right]$ dithiophene $\left.)\right)$-alt-(5,5-(1',3'-di-2-thienyl-5', $7^{\prime}$-bis(2ethylhexyl)-benzo[1 $\left.1^{\prime}, 2^{\prime}-c: 4^{\prime}, 5^{\prime}-c^{\prime}\right]$ dithiophene-4,8-dione)] (PBDB-TSF or PCE13).

$\mathrm{C}_{12} \mathrm{~N}_{3}$ compound was synthesized by reacting $\mathrm{NaN}_{3}$ with 1,12-dibromododecane (see details in ESI $\dagger$ ). $\mathrm{P} 3 \mathrm{HT}: \mathrm{PC}_{61} \mathrm{BM}$ blend (1:0.8 ratio) was dissolved in chlorobenzene at $60{ }^{\circ} \mathrm{C}$ for 3 hours. The final concentrations were $15 \mathrm{mg} \mathrm{mL}^{-1}$ of P3HT and $12 \mathrm{mg} \mathrm{mL}^{-1}$ of $\mathrm{PC}_{61} \mathrm{BM}$. The solution was cooled down at room temperature, and different amounts of additive were incorporated in chlorobenzene into P3HT: $\mathrm{PC}_{61} \mathrm{BM}$ solution. The ratio of additive was determined in weight percent (wt\%) compared to the acceptor $\left(\mathrm{PC}_{61} \mathrm{BM}\right)$ content. These solutions were either spin-coated or drop-casted, depending on the aimed characterization.

\section{Mechanical properties}

Young's modulus was measured by traction on Q800 Dynamic Mechanical Analysis (DMA) from TA Instruments. The selfstanding thin film $(\approx 10 \mu \mathrm{m}$ thick) was clamped, and a preload force of $0.05 \mathrm{~N}$ was applied until $0.05 \%$ strain. We used the mode strain rate at $20 \% \mathrm{~min}^{-1}$ to failure. The tensile test has its limitations.

Young's modulus can be determined by buckling technique initially described by Stafford et $a l^{38}$ The method is based on the formation of wrinkles in a relatively rigid film on a relatively compliant substrate under compressive strain. ${ }^{39}$ The tensile modulus of the film $\left(E_{\mathrm{f}}\right)$ is correlated to the modulus of the substrate $\left(E_{\mathrm{s}}\right)$, the thickness of the coated film $\left(t_{\mathrm{f}}\right)$, the wavelength of the buckles $\left(\lambda_{\mathrm{b}}\right)$, and the Poisson's ratios of the film and substrate $\left(\nu_{\mathrm{f}}\right.$ and $\left.\nu_{\mathrm{s}}\right):^{38}$

$$
E_{\mathrm{f}}=3 E_{\mathrm{s}}\left(\frac{1-\nu_{\mathrm{f}}^{2}}{1-\nu_{\mathrm{s}}^{2}}\right)\left(\frac{\lambda_{\mathrm{b}}}{2 \pi t_{\mathrm{f}}}\right)^{3}
$$

The Poisson's coefficient was taken at 0.35 for polymers and blend such as PEDOT:PSS, ${ }^{40} \mathrm{P} 3 \mathrm{HT}: \mathrm{PC}_{61} \mathrm{BM},{ }^{41}$ or PCE10: $\mathrm{PC}_{61} \mathrm{BM}$ in accordance with the literature.

\section{Thermal analysis}

The variation of storage modulus and the loss tangent $(\tan \delta)$ measured with Q800 Dynamic Mechanical Analysis (DMA) from TA Instruments, as a function of the temperature. We used infrared spectroscopy FTIR Cary 680 from Agilent, thermal gravimetric analysis (TGA) TG 209 from Netzsch and differential scanning calorimetry (DSC) TA Discovery 250.

\section{Surface analysis and imaging}

Optical microscope (Nikon eclipse LV100POL) mounted with a camera was used to observe the surface. Atomic force microscopy (AFM) from Bruker ${ }^{\circledR}$ was used to image the surface topography of a sample by analyzing point by point with a local probe scan. The images were taken in ScanAsyst mode (constant force, frequency of $2 \mathrm{kHz}$ ). The UV-Visible absorption spectra was measured using a UV-vis-NIR spectrophotometer (JASCO V-570).

\section{GIWAXS characterization}

Grazing-Incidence Wide-Angle X-ray Scattering (GIWAXS) is a versatile technique for characterizing an object at the nanoscale structure. 2D GIWAXS experiments were performed at D1 beamline at the Cornell High Energy Synchrotron Source. The beamline energy was $1.17 \AA$, and the sample detector distance was $167.5 \mathrm{~mm}$. An exposure time of $5 \mathrm{~s}$ was used for ex situ experiments. X-ray incidence angle was fixed at an optimal angle of $0.12^{\circ}$ probing $\mathrm{P} 3 \mathrm{HT}: \mathrm{PC}_{61} \mathrm{BM}$ film and minimizing the signal from the substrate. 2D GIWAXS image is reshaped with GIXSGUI software. ${ }^{42}$ The reshaping is a simple twodimensional image transformation taking account of some geometric and intensity correction resulting to a missing wedge image.

\section{OPV devices}

Glass patterned with $140 \mathrm{~nm}$ of indium tin oxide (ITO) substrates were cleaned by an ultrasonic bath with sodium dodecyl sulfate solution (SDS), deionized water, acetone, and isopropanol. UV-Ozone cleaner was used for $15 \mathrm{~min}$ to remove all organic residues and to improve the wettability of PEDOT:PSS. We used PEDOT:PSS AI 4083 from Heraeus Clevios as a hole transport layer (HTL). After a pre-filtration ( $0.25 \mu \mathrm{m}$ disc), the PEDOT:PSS mixture was deposited by spin coating (4000 rpm, $50 \mathrm{~s}, 2000 \mathrm{rpm} \mathrm{s}^{-1}$ ). Thermal treatment was performed at $140{ }^{\circ} \mathrm{C}$ for $10 \mathrm{~min}$. The thickness was measured by a profilometer with average values of $60 \pm 5 \mathrm{~nm}$.

P3HT:PC ${ }_{61}$ BM mixture with additives, was deposited by spin coating at $500 \mathrm{rpm}$ during $20 \mathrm{~s}$. We kept the cells in a Petri dish overnight. Then, annealing was done at $140{ }^{\circ} \mathrm{C}$ for $10 \mathrm{~min}$. PCE10 : $\mathrm{PC}_{71} \mathrm{BM}\left(1: 1.5\right.$, w/w, $\left.25 \mathrm{mg} \mathrm{mL}^{-1}\right)$ was mixed in chlorobenzene for 2 hours at $70{ }^{\circ} \mathrm{C}$ prior spin coating at $2000 \mathrm{rpm}$ for $60 \mathrm{~s}$. The samples were rinsed with $60 \mu \mathrm{L}$ of methanol at $4000 \mathrm{rpm}$ for $30 \mathrm{~s}$. Then, they were kept under vacuum for $30 \mathrm{~min}$ prior further deposition. $0.6 \mathrm{~nm}$ of lithium fluoride (LiF) was evaporated on top of P3HT:PC ${ }_{61} \mathrm{BM}$ and PCE10:PC ${ }_{71} \mathrm{BM}$.

PCE13:IT-4F $\left(1: 1, \mathrm{w} / \mathrm{w}, 20 \mathrm{mg} \mathrm{mL}^{-1}\right)$ mixture was spincoated (2000 rpm for $60 \mathrm{~s}$ ) on top of AI4083, no annealing was required. (2-(1,10-phenanthrolin-3-yl)naphth-6-yl)diphenylphosphine (Phen-NaDPO) as cathode interfacial material $0.5 \mathrm{mg} \mathrm{mL}^{-1}$ in isopropanol) was spin-coated at $2000 \mathrm{rpm}$ for $30 \mathrm{~s}$ on top of this active layer. Finally, we evaporated aluminum metal $(100 \mathrm{~nm})$ on all the cells. The area was $10 \mathrm{~mm}^{2}$. Organic solar cells were tested under AM 1.5G solar irradiation, in the nitrogen glove box, by solar simulator from Newport. 


\section{Results and discussion}

\section{Preamble - cross-linking characterization}

Due to the thermodynamic instability of P3HT:PC ${ }_{61} \mathrm{BM}$ active layer, the diazido additives have been successfully used to stabilize the structure over time by decreasing the diffusion of the $\mathrm{PC}_{61} \mathrm{BM},{ }^{18,19,26}$ and here, we explore the possible improvement of the stretchability of the BHJ through this cross-linking approach. The reaction of fullerene with organic diazides produces "azafulleroids". The mechanism of the reaction between diazide with $\mathrm{PC}_{61} \mathrm{BM}$ is shown in Fig. 2a. Under heat treatment, bis-azide molecules react selectively on the fullerene by a 1,3-cycloaddition and release two dinitrogen molecules. ${ }^{43}$ Differential scanning calorimetry (DSC), thermogravimetric analysis (TGA), and infrared spectroscopy have been carried out to prove the selective reaction of cross-linker molecules on the fullerene.

Fig. $2 \mathrm{~b}-\mathrm{f}$ demonstrates the thermal change of $\mathrm{PEG}_{3} \mathrm{~N}_{3}$ as cross-linker. The thermal characterizations of all other crosslinkers $\mathrm{P} 3 \mathrm{HT}$, and $\mathrm{PC}_{61} \mathrm{BM}$ are shown in the ESI. $\dagger$ The acceptor $\mathrm{PC}_{61} \mathrm{BM}$ presents two endothermic peaks at 247 and $280{ }^{\circ} \mathrm{C}$ (Fig. S2, ESI $\dagger$ ), corresponding to the crystallization and the melting transition, respectively. ${ }^{44}$ The donor P3HT exhibits a $T_{\mathrm{g}}$ between 100 and $140{ }^{\circ} \mathrm{C}$ and a melting point at $220{ }^{\circ} \mathrm{C}$ (Fig. S2, ESI $\dagger$ ). For $\mathrm{PEG}_{3} \mathrm{~N}_{3}$ cross-linker, the TGA displays a rapid weight loss after $150{ }^{\circ} \mathrm{C}$ (Fig. 2b). The decomposition of azide function into dinitrogen is not seen as the decomposition of the entire molecule hides it. For $\mathrm{PEG}_{n} \mathrm{~N}_{3}$, the thermal analysis reveals a weight loss of $6.5 \%$ between 140 and $180{ }^{\circ} \mathrm{C}$, revealing the azide decomposition. Firstly, the molecule decomposes theoretically, by liberating four nitrogen atoms from the two azide groups, corresponding to an expected $5 \%$ weight loss $\left(4 \times M_{\mathrm{N}} / M_{\mathrm{n}}=\right.$ $56 / 1100)$. Then a second weight loss is observed from 180 to $220{ }^{\circ} \mathrm{C}$, indicating the decomposition of the molecules. DSC was performed at several thermal ranges: from $-90{ }^{\circ} \mathrm{C}$ to $250{ }^{\circ} \mathrm{C}$ (Fig. S2, ESI $\dagger$ ) and from room temperature to $160{ }^{\circ} \mathrm{C}$ (Fig. 2c) to determine the thermal properties accurately. Below $160{ }^{\circ} \mathrm{C}$,

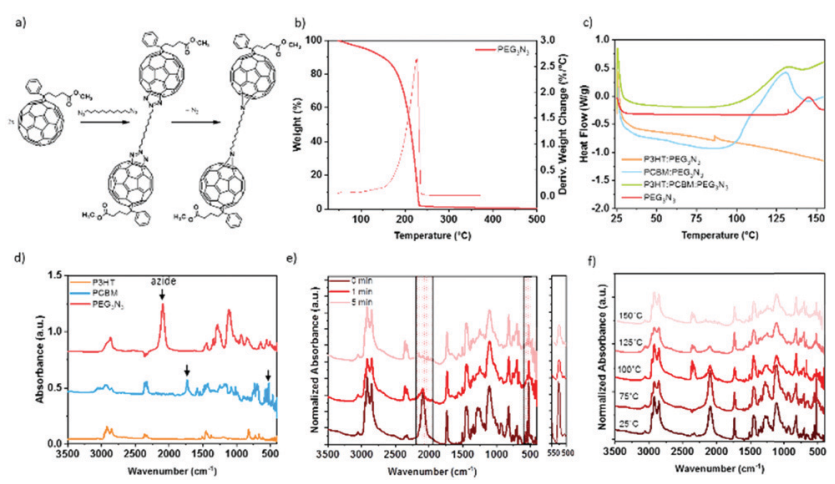

Fig. 2 (a) Scheme of reaction between bis-azide and $\mathrm{PC}_{61} \mathrm{BM}$ molecule under heat treatment. (b) Thermal gravimetric analysis of cross-linkers $\mathrm{PEG}_{3} \mathrm{~N}_{3}$. (c) DSC analysis of $\mathrm{PEG}_{3} \mathrm{~N}_{3}$ mixed with either P3HT (1:1) or $\mathrm{PC}_{61} \mathrm{BM}(1: 1)$, or P3HT:PC ${ }_{61} \mathrm{BM}(1: 1: 1)$. (d) FTIR spectra of the precursors before cross-linking. (e) Kinetic of cross-linking via monitoring P3HT:PC61BM:PEG $\mathrm{N}_{3}$ after thermal annealing at $150{ }^{\circ} \mathrm{C}$. (f) Temperature effect on $\mathrm{P} 3 \mathrm{HT}: \mathrm{PC}_{61} \mathrm{BM}: \mathrm{PEG}_{3} \mathrm{~N}_{3}$, for $5 \mathrm{~min}$.
$\mathrm{PEG}_{3} \mathrm{~N}_{3}$ exhibits an exothermic peak onset at $132{ }^{\circ} \mathrm{C}$, corresponding to the decomposition of the azide function. Similarly, $\mathrm{PEG}_{n} \mathrm{~N}_{3}$ displays a transition peak that starts at $29{ }^{\circ} \mathrm{C}$, which is the melting of the molecule, while the decomposition of the bis-azide is found at the onset of $143{ }^{\circ} \mathrm{C}$ (see Fig. S2, ESI $\dagger$ ). Thermal annealing up to $200{ }^{\circ} \mathrm{C}$ reveals the decomposition of both components above $170{ }^{\circ} \mathrm{C}$, in agreement with TGA.

DSC was carried out with cross-linkers mixed with P3HT or $\mathrm{PC}_{61} \mathrm{BM}$, to prove the selectivity of the cross-linking and the temperature range, as plotted in Fig. 2c. For $\mathrm{PEG}_{3} \mathrm{~N}_{3}$, the DSC curve in the presence of $\mathrm{P} 3 \mathrm{HT}$ does not show any change, while an exothermic peak with a maximum at $125{ }^{\circ} \mathrm{C}$ is observed in the presence of $\mathrm{PC}_{61} \mathrm{BM}$. This confirms the selectivity of the reaction between $\mathrm{PC}_{61} \mathrm{BM}$ and the bis-azide molecules.

Kinetics of reaction the bis-azide function can be detected by attenuated total-reflectance Fourier transform infrared (ATRFTIR) spectroscopy (Fig. 2d). The infrared spectra of each precursor are presented in Fig. $2 \mathrm{~d}-\mathrm{f}$ and Fig. S3 (ESI $\dagger$ ). The peak at $2090 \mathrm{~cm}^{-1}$ is attributed to azide functions, for all the cross-linkers: $\mathrm{PEG}_{3} \mathrm{~N}_{3}, \mathrm{C}_{12} \mathrm{~N}_{3}$, and $\mathrm{PEG}_{n} \mathrm{~N}_{3}$. $\mathrm{PC}_{61} \mathrm{BM}$ shows several FTIR $\mathrm{C}=\mathrm{C}$ characteristics peaks at 1464 and $526 \mathrm{~cm}^{-1}$, due to the $\mathrm{C}_{60}$ cage, and $1730 \mathrm{~cm}^{-1}$ corresponding to the $\mathrm{C}=\mathrm{O}$ bond of the butyric acid methyl ester, in agreement with the literature. ${ }^{45}$ IR spectra of P3HT:PC ${ }_{61} \mathrm{BM}: \mathrm{PEG}_{3} \mathrm{~N}_{3}$ with weight ratio $(1: 0.8: 0.4)$ after thermal annealing at $150{ }^{\circ} \mathrm{C}$ during 0,1 , and $5 \mathrm{~min}$ is shown in Fig. 2e. The intensity of the azide peak $\left(\nu_{\mathrm{N}_{3}}=2090 \mathrm{~cm}^{-1}\right)$ was reduced by $70 \%$ after only $1 \mathrm{~min}$ at $150{ }^{\circ} \mathrm{C}$ and disappeared totally in 5 min of heating. At the same time, the heat treatment decreases the vibrational bands of the $\mathrm{C}_{60}$ cage of the $\mathrm{PC}_{61} \mathrm{BM}\left(526 \mathrm{~cm}^{-1}\right)$. This decrease is attributed to side group attachment of fullerenes to additive molecules, as described by the mechanism in Fig. 2a. This behavior is observed for the other cross-linkers in Fig. S3 (ESI $\dagger$ ). In Fig. 2f, all materials were annealing for $5 \mathrm{~min}$ at various temperatures before the FTIR analysis. At room temperature and $75{ }^{\circ} \mathrm{C}$, no change is detected, while above $100{ }^{\circ} \mathrm{C}$, the intensity of azide peak decreases, in agreement with the DSC data. The kinetic of curing depends on the temperature, indicating a complete reaction at $150{ }^{\circ} \mathrm{C}$ of the azide group with the fullerene. Elevated temperature accelerates the cross-linking rate, as observed in Fig. 2f. According to these results, a 15 min curing at $150{ }^{\circ} \mathrm{C}$ was proceeded for each component to assure the complete selective reaction of azide and $\mathrm{PC}_{61} \mathrm{BM}$, unless stated otherwise.

\section{Film morphology in the presence of additives}

In the previous section, the cross-linking process was studied and validated. The diazide cross-linkers react selectively with $\mathrm{PC}_{61} \mathrm{BM}$ molecules. From now, the preparation of P3HT: $\mathrm{PC}_{61} \mathrm{BM}$ (1:0.8 ratio) film involves blending fixed amounts of reactive cross-linkers or elastomers with the organic semiconductors. Solutions were mixed to achieve a target additive content in weight percent (wt\%) compared to the acceptor weight. The blend solution was spin-coated and annealed at $150{ }^{\circ} \mathrm{C}$ for $15 \mathrm{~min}$ before testing. In this section, the impact of the addition of cross-linkers and rubbers into the active layer on 

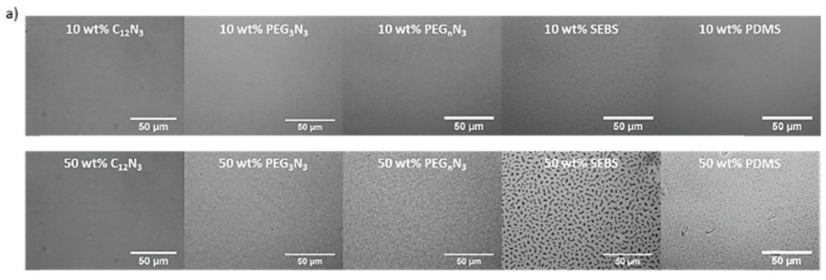

b)

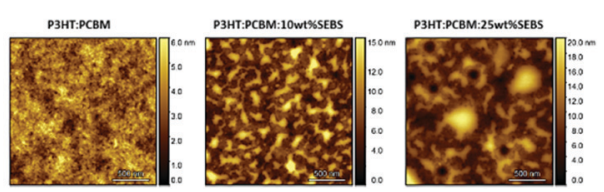

Fig. 3 (a) Optical micrographs of $P 3 H T: P C_{61} B M$ in the presence of additives as indicated in the picture after annealing. (b) AFM images of $\mathrm{P} 3 \mathrm{HT}: \mathrm{PC}_{61} \mathrm{BM}$ blended with and without SEBS.

the morphology, mechanical properties along photovoltaic characteristics are studied.

Optical microscopy allows us to understand, to some extent, phase separation. Thus, Fig. 3a and Fig. S4 (ESI $\dagger$ ) show the micro-texture change in the presence of additives into P3HT:PC ${ }_{61} \mathrm{BM}$ blends after thermal annealing at $150{ }^{\circ} \mathrm{C}$ for $15 \mathrm{~min}$. The phase segregation seems unchanged on the investigated scale with $10 \mathrm{wt} \%$ additives (Fig. 3a). With the increase of the additive content, phase separation is denoted. In particular, for SEBS and PDMS at $50 \mathrm{wt} \%$, the elastomer and the blend appear highly segregated (Fig. 3a). The size of domains reaches up to $10 \mu \mathrm{m}$ for $50 \mathrm{wt} \%$ SEBS and about $5 \mu \mathrm{m}$ for $50 \mathrm{wt} \%$ PDMS. Furthermore, the morphology of P3HT:PC ${ }_{61} \mathrm{BM}$ in the presence of SEBS was analyzed by atomic force microscopy (AFM) (Fig. 3b). A phase-separated blend is visibly observed for different content, even as low as $10 \mathrm{wt} \%$ of SEBS (about $5 \mu \mathrm{m}$ long). The poor miscibility of an elastomer with the blend could explain the phase separation.

P3HT:PC ${ }_{61} \mathrm{BM}$ active layer is thermodynamically unstable. ${ }^{46}$ The morphology changes with temperature. This problem is well known in the literature and ascribed to the dissemination and $\mathrm{PC}_{61} \mathrm{BM}$ crystallization molecules under thermal annealing. ${ }^{47,48}$ Crystallization could demonstrate dramatic effects on photovoltaic performances, ${ }^{46}$ but also on mechanical properties. ${ }^{21,49,50}$ While mechanical stability is the main concern in this work, the prevention of $\mathrm{PC}_{61} \mathrm{BM}$ crystallization remains essential to ensure elasticity. After 60 hours thermal annealing at $150{ }^{\circ} \mathrm{C}, \mathrm{PC}_{61} \mathrm{BM}$ molecules diffuse into the active layer and form microcrystals, as shown in Fig. S5 and S6 (ESI $\dagger)$. Without additive, after heat treatment, $\mathrm{PC}_{61} \mathrm{BM}$ molecules form microscopic size crystals (about $20 \mu \mathrm{m}^{2}$ ). When $\mathrm{C}_{12} \mathrm{~N}_{3}$ is added, the cross-linking of the $\mathrm{PC}_{61} \mathrm{BM}$ molecules by $-\mathrm{N}_{3}$ groups prevents the growth of $\mathrm{PC}_{61} \mathrm{BM}$ microcrystals in the photoactive layer after 60 hours at $150{ }^{\circ} \mathrm{C}$. The same effect is observed with $\mathrm{PEG}_{3} \mathrm{~N}_{3}$ even after $60 \mathrm{~h}$ at $150{ }^{\circ} \mathrm{C}$. In the presence of $10 \mathrm{wt} \% \mathrm{PEG}_{n} \mathrm{~N}_{3}$, the morphology after aging is not stabilized. This shows that $10 \mathrm{wt} \% \mathrm{PEG}_{n} \mathrm{~N}_{3}$ cross-linkers do not have the desired effect. This trend may be explained with the weight ratio of $\mathrm{PEG}_{n} \mathrm{~N}_{3}$; there is only one azide function for about 24 molecules of $\mathrm{PC}_{61} \mathrm{BM}$, while the two other cross-linkers are in a 1 : 1.4 ratio azide compared to $\mathrm{PC}_{61} \mathrm{BM}$. Consequently, only a few of the fullerene derivatives are cross-linked with $\mathrm{PEG}_{n} \mathrm{~N}_{3}$ and may explain the difference in cross-linker stability behavior compared to $\mathrm{C}_{12} \mathrm{~N}_{3}$ and $\mathrm{PEG}_{3} \mathrm{~N}_{3}$. This cross-linking prevents the crystallization of $\mathrm{PC}_{61} \mathrm{BM}$ during heat treatment at $150{ }^{\circ} \mathrm{C}$. Several reports confirm the favorable effect of cross-linking on thermal aging. ${ }^{18,30,51}$ The embedding of $\mathrm{P} 3 \mathrm{HT}: \mathrm{PC}_{61} \mathrm{BM}$ with elastomeric SEBS slows down the diffusion of $\mathrm{PC}_{61} \mathrm{BM}$ molecules as a net reduction of the crystal is seen compared to the neat P3HT:PC ${ }_{61}$ BM sample (Fig. S6, ESI $\dagger$ ). This behavior can be beneficial for long-term stability.

UV-Visible absorption has been used for measuring the optical properties of semiconductors in films. The UV-vis spectra for as-casted films of $\mathrm{PC}_{61} \mathrm{BM}, \mathrm{P} 3 \mathrm{HT}$, and P3HT:PC ${ }_{61} \mathrm{BM}$ blend is shown in Fig. S7a, (ESI $\dagger$ ). $\mathrm{PC}_{61} \mathrm{BM}$ shows a low optical absorbance between 400 to $800 \mathrm{~nm}$ and a maximum at $335 \mathrm{~nm}$. P3HT exhibits a broad absorption peak centered at $550 \mathrm{~nm}$ with three significant vibronic polymer bands at 520, 553, and $602 \mathrm{~nm}$ due to the relatively good organization of the polymer chains in the film. ${ }^{52,53}$ The additive effect on P3HT:PC ${ }_{61} \mathrm{BM}$ film morphology was investigated on the annealed thin films. Fig. S7b (ESI $\dagger$ ) shows the absorption spectra normalized to the $\mathrm{PC}_{61} \mathrm{BM}$ maximum (335 nm). An increase of the absorbance intensity at $520 \mathrm{~nm}$ is observed for the cross-linked film with azide-based molecules, indicating an increase in the degree of P3HT aggregation. On the contrary, the elastomer addition decreases the absorption intensity with a blue shift at $510 \mathrm{~nm}$. This indicates that the degree of P3HT aggregation decreases in the presence of elastomeric additives.

Understanding the effect of the additives on the morphology is critical to ensuring good charge transport in the OPV device. Fig. 4a corresponds to the GIWAXS 2D image obtained for P3HT:PC ${ }_{61} \mathrm{BM}$ thin film. The scattering patterns along with $q_{\mathrm{z}}$ correspond to crystallized P3HT lamellar stacking with a primary edge-on orientation. The Bragg peaks rising at $q_{z}=3.8,7.5$ and $11.5 \mathrm{~nm}^{-1}$ correspond to P3HT lamellae layer plans (100), (200), and (300), respectively. The (010) peak at $q \sim 16.5 \mathrm{~nm}^{-1}$, along $q_{x y}$, is typical for P3HT $\pi-\pi$ stacking, with a spacing of $0.37 \mathrm{~nm}$. The ring positioned at $q=14.2 \mathrm{~nm}^{-1}$ is due to scattering from disordered $\mathrm{PC}_{61} \mathrm{BM}$ molecules. This is in agreement with previous studies. ${ }^{54-57}$

Fig. 4b-e and Fig. S9 (ESI $\dagger$ ) demonstrate the impact of the additives on the GIWAXS pattern. In agreement with absorption data, an increase in the intensity of the P3HT lamellae peak is observed in the presence of cross-linker molecules $\left(\mathrm{C}_{12} \mathrm{~N}_{3}\right.$, $\mathrm{PEG}_{3} \mathrm{~N}_{3}, \mathrm{PEG}_{n} \mathrm{~N}_{3}$ ). Fig. $4 \mathrm{c}$ shows strong out-of-plane alkyl diffraction for the latest molecules, while the blending with SEBS and PDMS indicates a decrease of intensity and broadening of the peak. Table 1 presents the calculated crystalline parameters of alkyl chain stacking and $\pi-\pi$ stacking extracted from films with different additives. Table 1 exhibits a negligible change in $d$-spacing of (100) lamellar and (010) aromatic peaks for all additives. This indicates that there are no interactions between the additives and P3HT. No dramatic change in correlation length (CCL) is observed in the presence of cross-linkers. This suggests that the cross-linking does not disorder P3HT polymer, which is not surprising. In the presence of cross-linkers, the 

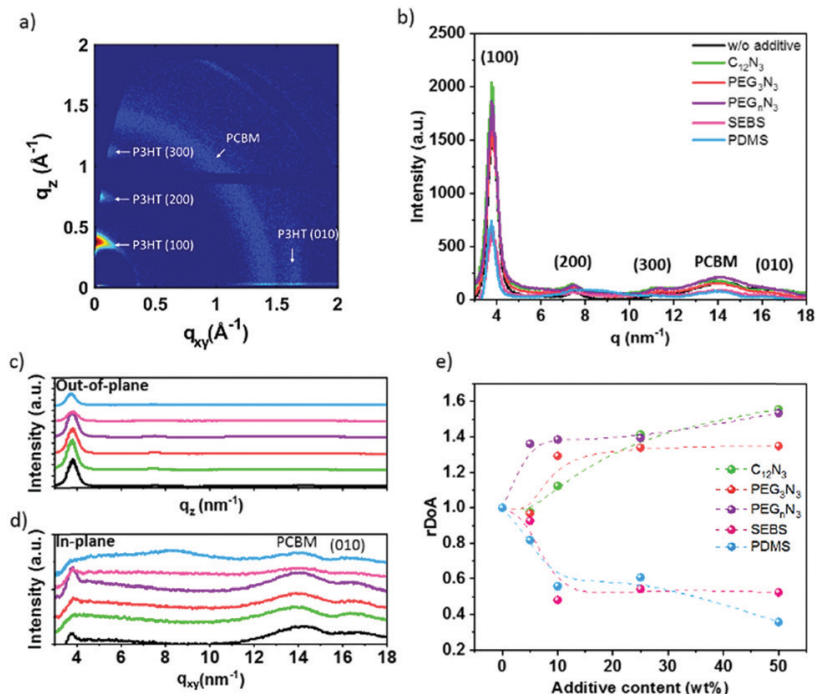

Fig. 4 (a) Two-dimensional GIWAXS image of P3HT:PC ${ }_{61} B M$ thin film. (b) Effect of the additives on 2D GIWAXS diffraction pattern: (b) fully integrated, (c) out-of-plane integrated and (d) in-plane integrated signal, and (e) the relative degree of aggregation to neat $\mathrm{P} 3 \mathrm{HT}: \mathrm{PC}_{61} \mathrm{BM}$ of (100) peak.

Table 1 Summary of GIWAXS peak fitting results. The additives were introduced at $50 \mathrm{wt} \%$ compared to $\mathrm{PC}_{61} \mathrm{BM}$, i.e., $\mathrm{P} 3 \mathrm{HT}: \mathrm{PC}_{61} \mathrm{BM}$ :additive at $1: 0.8: 0.4$. Lamellar stacking was taken from the (100) peak, and the $\pi-\pi$ stacking was extracted from the (010) peak

\begin{tabular}{|c|c|c|c|c|c|}
\hline \multirow[b]{2}{*}{ Additive } & \multirow[b]{2}{*}{$\begin{array}{l}\mathrm{MW} \\
\left(\mathrm{g} \mathrm{mol}^{-1}\right)\end{array}$} & \multicolumn{2}{|c|}{ Lamellar stacking } & \multicolumn{2}{|c|}{$\pi-\pi$ stacking } \\
\hline & & $\begin{array}{l}d \text {-Spacing } \\
(\mathrm{nm})\end{array}$ & $\begin{array}{l}\text { CCL } \\
(\mathrm{nm})\end{array}$ & $\begin{array}{l}d \text {-Spacing } \\
(\mathrm{nm})\end{array}$ & $\begin{array}{l}\text { CCL } \\
(\mathrm{nm})\end{array}$ \\
\hline w/o additive & - & 1.65 & 11.8 & 0.37 & 3.7 \\
\hline $\mathrm{C}_{12} \mathrm{~N}_{3}$ & 252 & 1.66 & 11.5 & 0.38 & 3.8 \\
\hline $\mathrm{PEG}_{3} \mathrm{~N}_{3}$ & 244 & 1.65 & 11.3 & 0.38 & 4.1 \\
\hline $\mathrm{PEG}_{n} \mathrm{~N}_{3}$ & 1100 & 1.65 & 11.5 & 0.38 & 3.6 \\
\hline SEBS & - & 1.65 & 11.7 & 0.38 & 4.9 \\
\hline PDMS & - & 1.67 & 14.3 & 0.38 & 4.9 \\
\hline
\end{tabular}

intensity of the $\mathrm{PC}_{61} \mathrm{BM}$ ring increases, and a slight shift to a lower $q$ value is perceived from 14.0 to $13.7 \mathrm{~nm}^{-1}$ for $\mathrm{C}_{12} \mathrm{~N}_{3}$ and $13.8 \mathrm{~nm}^{-1}$ for $\mathrm{PEG}_{3} \mathrm{~N}_{3}$. This could be due to the cross-linking effect on $\mathrm{PC}_{61} \mathrm{BM}$.

On the other hand, the elastomer blending tends to increase the CCL for the $\pi-\pi$ stacking, promoting phase separation of $\mathrm{P} 3 \mathrm{HT}: \mathrm{PC}_{61} \mathrm{BM}$, as confirmed by the optical image. PDMS presents a significant increase of the CCL in both lamellar and $\pi-\pi$ stacking and $\mathrm{PC}_{61} \mathrm{BM}$ scattering position center does not shift in the presence of elastomers. However, the crystallinity of $\mathrm{PC}_{61} \mathrm{BM}$ decreases in the embedded film with SEBS and PDMS.

The previous result revealed no change in the correlation length with cross-linkers. This effect does not take into account the volume distribution of the material. The quantification of the material blend could play a crucial role in understanding the morphology of film formation. The relative degree of crystalline aggregation (rDoA), also called the relative degree of crystallinity, is given in eqn (2) ${ }^{58}$ It is proportional to the azimuthal integration of a Bragg peak (in our case, it will concern (100) P3HT lamella peak), as seen in Fig. S10 (ESI $\dagger$ ), taking account of a geometrical correction factor $\sin (\chi)$.

$$
\operatorname{rDoA} \propto \int_{0}^{\frac{\pi}{2}} \sin (\chi) I(\chi) \mathrm{d} \chi
$$

The integration result was extracted for all compositions and normalized to material volume (density and thickness). rDoA was determined as relative to pristine $\mathrm{P} 3 \mathrm{HT}: \mathrm{PC}_{61} \mathrm{BM}$, as plotted in Fig. 4e. The addition of cross-linkers increases the aggregation of P3HT lamella. On the contrary, the addition of elastomer decreases the relative crystallinity of the polymer to $50 \%$ of the neat blend; besides that, the CCL increases. This is in agreement with the UV-vis spectral results, which reveal reduced photophysical aggregation. The elastomer, therefore, makes the film generally less ordered at multiple scales. The next step is to investigate how the additive affects the mechanical and optoelectronic properties.

\section{Mechanical properties}

The Young's moduli of P3HT: $\mathrm{PC}_{61} \mathrm{BM}$ mixed with additive are plotted in Fig. 5b and were deduced by strain-stress curves in Fig. 5a. The pristine P3HT: $\mathrm{PC}_{61} \mathrm{BM}$ shows Young's modulus of $2.1 \mathrm{GPa}$. This is comparable to the literature. ${ }^{10-13}$ The diazide cross-linker components decrease the elastic modulus of the P3HT: $\mathrm{PC}_{61} \mathrm{BM}$. The addition of $50 \mathrm{wt} \%$ cross-linker reduces P3HT: $\mathrm{PC}_{61} \mathrm{BM}$ modulus by 2.4-fold for $\mathrm{C}_{12} \mathrm{~N}_{3}, 2.9$-fold for $\mathrm{PEG}_{3} \mathrm{~N}_{3}$, and 4.6-fold for $\mathrm{PEG}_{n} \mathrm{~N}_{3}$. Similarly, with elastomer additives, the elastic modulus of $\mathrm{P} 3 \mathrm{HT}: \mathrm{PC}_{61} \mathrm{BM}$ film drops from $2.1 \mathrm{GPa}$ to $0.3 \mathrm{GPa}$ in the presence of $50 \mathrm{wt} \% \mathrm{SEBS}$, and to 0.7 GPa for $50 \mathrm{wt} \%$ PDMS. Two effects due to the incorporation of additives are distinguishable: (1) the tensile modulus of a P3HT: $\mathrm{PC}_{61} \mathrm{BM}$ is drastically reduced with the additive
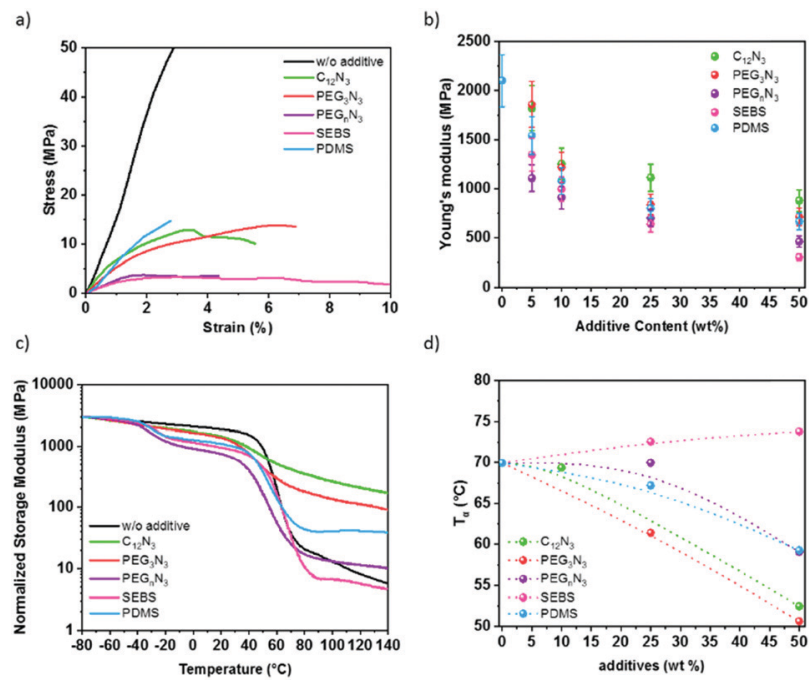

Fig. 5 Effect of the additives on the mechanical properties i.e. (a) stressstrain curves with 50 wt\% additive content. (b) Average Young's modulus according to the weight percent of additives added into P3HT:PC ${ }_{61} \mathrm{BM}$ blend prior to annealing. (c) Temperature dependence of storage modulus for the P3HT:PC ${ }_{61} \mathrm{BM}$ :additive composites $(1: 0.8: 0.4)$, i.e., in the presence of $50 \mathrm{wt} \%$ additives. (d) Summary of the alpha temperature. 
concentration, and (2) the increase of the chain length of the cross-linker increases the softening effect in the semiconductors blend. The addition of small molecules has a plasticizing effect, which softens rigid polymers, while it is not perturbing significantly the crystallinity of P3HT as shown earlier. The Young's moduli of films decrease with elastomer blending, which agrees with the incorporation of soft rubber in the film concomitantly with the decrease of relative crystallinity of P3HT aggregates, deduced by UV-visible spectra and GIWAXS.

Furthermore, Young's modulus determines the ability to resist stress, i.e., the material's stiffness. The material softness is not automatically related to the ability to be stretched. The elasticity of the material needs to be determined. For that reason, the fracture strain was extracted from a tensile test for an average of three samples. Table 2 shows a summary of the mechanical properties deduced from the measurements on 10-20 $\mu \mathrm{m}$ thick films. While the elastic modulus decreases exponentially with the additive content due to a plasticizer effect, the fracture strain does not increase as much. The fracture strain increases by $\sim 50 \%$ for all cross-linked films. Surprisingly, PDMS does not contribute to the elasticity more than the cross-linkers. In comparison, some studies show high deformability of P3HT nanowires blended with PDMS elastomer keeping the mobility constant under $100 \%$ strain. ${ }^{27,28}$ In our work, the presence of $\mathrm{PC}_{61} \mathrm{BM}$ as nano-charges might stiffen the resulting blends compared to only polymer/elastomer blends. On the other hand, the blending of P3HT: $\mathrm{PC}_{61} \mathrm{BM}$ with elastomers promotes the elasticity to $54 \%$ strain with 50 wt\% SEBS. This suggests an excellent softening effect of SEBS, as previously seen for P3HT:SEBS composites. ${ }^{30}$

Fig. 5c shows the variation of storage modulus and the loss tangent $(\tan \delta)$ measured with dynamic mechanical analysis instrument (DMA), as a function of the temperature of P3HT: $\mathrm{PC}_{61} \mathrm{BM}$ thick film with different additives at $50 \mathrm{wt} \%$. The typical behavior of P3HT: $\mathrm{PC}_{61} \mathrm{BM}$ blend without additive presents a sharp decrease of the storage modulus at $60{ }^{\circ} \mathrm{C}$ from the glassy to the rubbery state, corresponding to the $\alpha$ relaxation of the layer ${ }^{59,60}$ (Fig. 5c). The glass transition temperature of the blend increases with increasing $\mathrm{PC}_{61} \mathrm{BM}$ content. This trend is in agreement with the result reported by Zhao et al. ${ }^{61}$ After this transition, the material keeps softening with no stable rubbery plateau observed, indicating a creep behavior. As far as films with additives are concerned, two types of behavior can be observed. For minor molecular weight additives $\left(\mathrm{C}_{12} \mathrm{~N}_{3}\right.$ and $\mathrm{PEG}_{3} \mathrm{~N}_{3}$ ), only one transition occurs in the same temperature

Table 2 Mechanical properties of P3HT:PC ${ }_{61} \mathrm{BM}$ with 50 wt\% additive. The letter $E$ states for elastic modulus. $T_{\alpha}$ is the alpha transition temperature extracted from DMA data at the maximum of the peak

\begin{tabular}{lccl}
\hline Additive & $E(\mathrm{MPa})$ & Fracture strain $(\%)$ & $T_{\alpha}\left({ }^{\circ} \mathrm{C}\right)$ \\
\hline w/o additive & 2103 & 4 & 70 \\
$\mathrm{C}_{12} \mathrm{~N}_{3}$ & 880 & 6 & 53 \\
$\mathrm{PEG}_{3} \mathrm{~N}_{3}$ & 715 & 7 & 51 \\
$\mathrm{PEG}_{n} \mathrm{~N}_{3}$ & 462 & 5 & 59 \\
$\mathrm{SEBS}$ & 303 & 54 & 74 \\
$\mathrm{PDMS}$ & 667 & 6 & 59
\end{tabular}

range as neat $\mathrm{P} 3 \mathrm{HT}: \mathrm{PC}_{61} \mathrm{BM}$ but with a less pronounced modulus drop. For macromolecular additives $\left(\mathrm{PEG}_{n} \mathrm{~N}_{3}\right.$, SEBS, and PDMS), an additional transition can be observed at a lower temperature $\left(-40\right.$ and $-20{ }^{\circ} \mathrm{C}$ ), corresponding to the $\alpha$ relaxation of the macromolecular additives themselves. The glass transition is $-20{ }^{\circ} \mathrm{C}$ for SEBS and $-40{ }^{\circ} \mathrm{C}$ for PDMS (Fig. S11, $\mathrm{ESI} \dagger$ ) which fits the first transition perceived for the P3HT:PC ${ }_{61}$ BM:additives blend. Additionally, another small drop above $100{ }^{\circ} \mathrm{C}$ is observed for SEBS corresponding probably to the $T_{\mathrm{g}}$ of the polystyrene blocks responsible of the physical crosslinking of the SEBS network.

Interestingly, with increasing the temperature above the transition of $\mathrm{P} 3 \mathrm{HT}: \mathrm{PC}_{61} \mathrm{BM}$ phase, a rubbery plateau is reached for all three samples indicating that no creep is observed in these conditions, on the opposition of neat films and films modified with low molecular weight additives. From the variation of loss tangent depicted in Fig. $5 d$, it can be seen that no significant modification of the $\alpha$ temperature is observed for the sample with SEBS, demonstrating poor interaction between SEBS and P3HT: $\mathrm{PC}_{61} \mathrm{BM}$ phase, due to the heterogeneity of the composite in accordance with the micrographs (Fig. 3). On the other side, a single glass transition is observed with all different compositions with a shift to lower temperature and a broader transition range, attesting to the miscibility of the additives with semiconductor polymer. Plasticizer addition results in a progressive decrease of the $\alpha$ relaxation, acting as a lubricant in polymer chains. ${ }^{62}$ Accordingly, the glass temperature depression occurring (Fig. 5d) attests to the softening effect, as suggested by the Young's modulus.

\section{Photovoltaic performances}

Photovoltaic performances were measured to investigate the influence of additives on photovoltaic efficiency. Fig. 6 shows the photovoltaic characteristics, namely the short-circuit current density $J_{\mathrm{sc}}$, the open-circuit voltage $V_{\mathrm{oc}}$, the fill factor
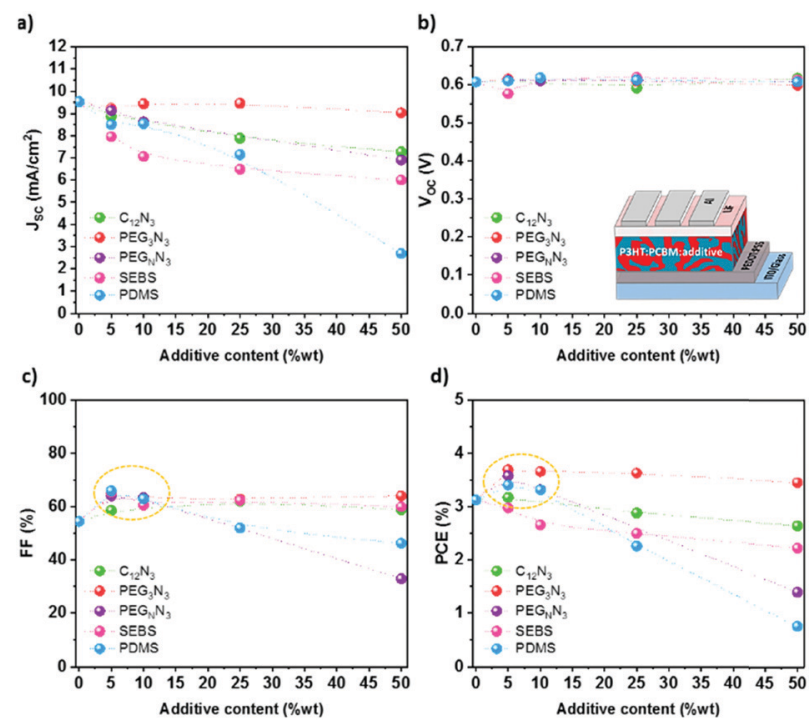

Fig. 6 Photovoltaic performances of P3HT:PC ${ }_{61} \mathrm{BM}$-based OPV in the function of the additive content. 
$\mathrm{FF}$, and the power conversion efficiency (PCE) in the function of the content of the additive. The $J-V$ characteristics curves are plotted in Fig. S12 (ESI $\dagger$ ). P3HT:PC ${ }_{61} \mathrm{BM}$ was blended with different amounts of additives (0, 5, 10, 25 and $50 \mathrm{wt} \%)$ and spin-coated on top of ITO coated with PEDOT:PSS.

The addition of an insulating ternary component into the blend does not significantly influence the $V_{\text {oc }}$, as observed in Fig. $6 \mathrm{~b}$. On the other hand, the $J_{\mathrm{sc}}$ decreases with the additive content, even if not significantly for $\mathrm{PEG}_{3} \mathrm{~N}_{3}$ (Fig. 6a). Below $10 \mathrm{wt} \%$, the increase of the photovoltaic efficiency (Fig. 6d) results from the balance between the increase in the fill factor and the decrease in the short-circuit current. Beyond $25 \mathrm{wt} \%$, the additions of high molecular weight polymer sharply decrease the photovoltaic operational characteristics, especially the short circuit current. At the same time, $\mathrm{C}_{12} \mathrm{~N}_{3}$ and $\mathrm{PEG}_{3} \mathrm{~N}_{3}$ based OPVs maintain excellent efficiency with more than $90 \%$ of their initial PCE. At $25 \mathrm{wt} \%$ SEBS, the PCE drops up to $20 \%$ compared to the initial PCE. In analogy with the mechanical measurements, a maximum additive content of $25 \mathrm{wt} \%$ allows up to $50 \%$ decrease of the Young Modulus and less than 25\% decrease of the PCE.

Diazide components have demonstrated their ability to improve the softness and to maintain good electrical properties for OPVs. It is worth noting that the apolar $\mathrm{C}_{12} \mathrm{~N}_{3}$ cross-linker and the polar $\mathrm{PEG}_{3} \mathrm{~N}_{3}$ cross-linker have relatively similar lengths and behave similarly as a stretchable additive for OPV. Thus, the polarity of the cross-linkers does not appear to play a significant role in the mechanical and electronics properties of the material systems studied here. While these cross-linkers are suitable for fullerene acceptors only, they require thermal curing, as shown by TGA and DSC analyses. However, solar cells fabrication without thermal annealing is beneficial for several reasons, including reducing process complexity, manufacturing speed, increasing embedded energy and limiting the exposition of thermally sensitive active layer to thermal treatment. The recent progress of our group in the OPV devices shows an efficiency of up to $17 \%$ without thermal annealing. ${ }^{63}$ This solar cell was made from a ternary PBDB-T2F:Y6: $\mathrm{PC}_{71} \mathrm{BM}$ bulk-heterojunction. Recently, the chlorination or fluorination of conjugated polymer has also demonstrated annealing-free OPVs with high crystallization and aggregation due to the intermolecular interactions between the halogens and carbon/hydrogen. ${ }^{64}$ The morphology is therefore optimized and ordered without requiring thermal annealing. While some new systems do not require thermal treatment, any strategy involving thermal annealings like diazide cross-linking or PDMS curing is highly undesirable to avoid a drastic drop in performance. Instead, the second strategy, i.e., the blending with a thermoplastic elastomer, does not require any additional step for curing since physical crosslinks will occur during the casting and drying process. It appears as the ideal pathway to be explored for high-efficiency and more thermally sensitive polymers. This method seems to have excellent versatility and is a straightforward technique to creating stretchability, and may be suitable for other acceptor/donor blends. Our study shows that physically cross-linked SEBS is a great candidate for improving the mechanical properties and keeping excellent photovoltaic performances when it is blended with P3HT: $\mathrm{PC}_{61} \mathrm{BM}$ at $25 \mathrm{wt} \%$ loadings or less. In the next section, we broaden our investigation to modern high-efficiency BHJ systems blended with SEBS.

\section{Other bulk heterojunction blends for high power conversion efficiency}

The SEBS additive was introduced to poly[4,8-bis(5-(2-ethylhexyl)thiophen-2-yl)benzo[1,2- $\left.b: 4,5-b^{\prime}\right]$ dithiophene-alt-3-fluorothieno[3,4- $b]$ thiophene-2-carboxylate] (PTB7-Th or PCE10) and $[6,6]$-phenyl- $\mathrm{C}_{71}$-butyric acid methyl ester $\left(\mathrm{PC}_{71} \mathrm{BM}\right)$ blends, also referred to PCE10:PC ${ }_{71} \mathrm{BM}$. Fig. 7a shows the chemical structure, the energy band diagram, the absorption spectra, and the $J-V$ curve associated with the PCE10:PC ${ }_{71} \mathrm{BM}$ blend at a weight ratio of $1: 1.5$. PCE10 polymer has a low bandgap $(1.6 \mathrm{eV})$, with a broad absorption between 500 and $800 \mathrm{~nm}$ with two peaks at 645 and $700 \mathrm{~nm}$. The solar spectrum between 300 and $800 \mathrm{~nm}$ is covered in a complementary manner by $\mathrm{PC}_{71} \mathrm{BM}$ blended with PCE10 (Fig. 7b). The solar cell layout is glass/ITO/ PEDOT:PSS/PCE10:PC ${ }_{71} \mathrm{BM} / \mathrm{LiF} / \mathrm{Al}$. This BHJ blend yields a PCE of up to $10 \%\left(J_{\mathrm{sc}}=17.3 \mathrm{~mA} \mathrm{~cm}{ }^{-2}, V_{\mathrm{oc}}=0.8 \mathrm{~V}, \mathrm{FF}=60.0 \%\right)$, in agreement with several reports. ${ }^{65-67}$

SEBS elastomer was diluted in chlorobenzene at $90{ }^{\circ} \mathrm{C}$, then mixed with PCE10: $\mathrm{PC}_{71} \mathrm{BM}$ solution $(1: 1.5)$ with $3 \mathrm{vol} \%$ 1,8-diiodooctane (DIO), and cast. SEBS elastomer content is
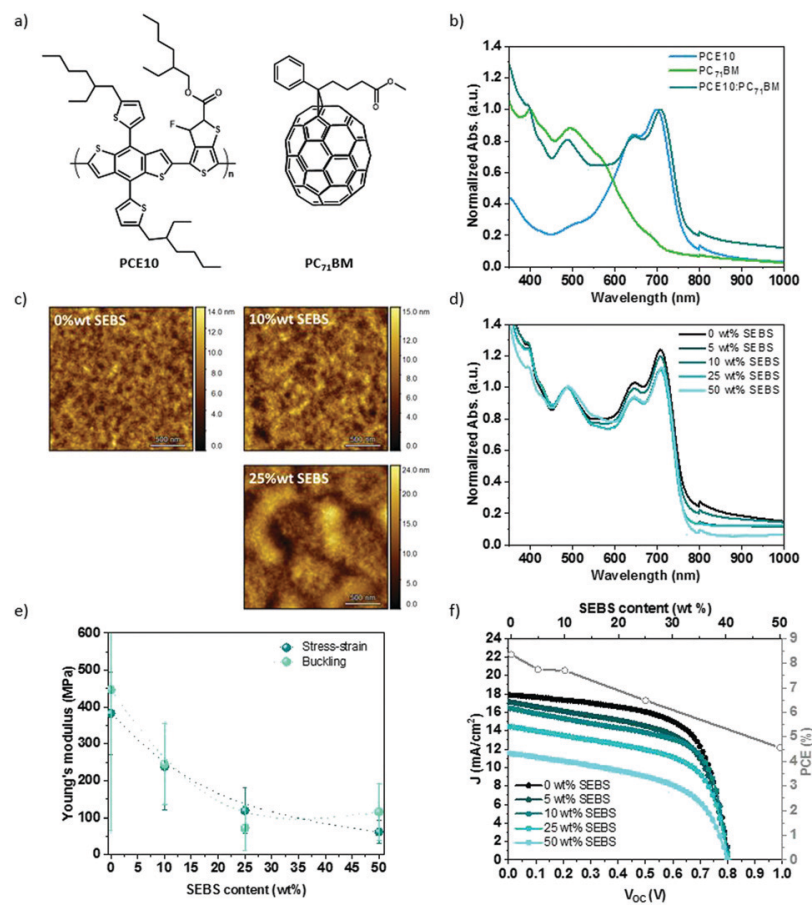

Fig. 7 PCE10: CC $_{71} \mathrm{BM}(1: 1.5)$ solar cell: (a) chemical structures, and (b) absorption spectra. (c) PCE10:PC ${ }_{71} \mathrm{BM}$ :SEBS morphology characterized by atomic force microscopy. (d) Absorption spectra of PCE10:PC ${ }_{71} B M$ film mixed with SEBS elastomer. (e) Young's moduli by stress-strain or buckling methods with different amounts of SEBS (wt/wt\% $P C_{71} B M$ ). (f) $J-V$ characteristics curves of PCE10:PC ${ }_{71} \mathrm{BM}$ with SEBS elastomer and associated PCE. 
determined by the amount relative to $\mathrm{PC}_{71} \mathrm{BM}$ weight. DIO is used to improve morphology. ${ }^{66}$ Fig. $7 \mathrm{c}$ and Fig. S13 (ESI $\dagger$ ) show the resulting morphology after spin-coating observed by atomic force microscopy (AFM) and optical microscope, respectively. Between 0 to $25 \mathrm{wt} \%$ SEBS, no drastic change is seen at the microscale. The addition of $50 \mathrm{wt} \%$ reveals a micro-phase separation of the polymers blend. AFM additionally characterized the morphology of the $\mathrm{BHJ}$ thin film. The roughness and the domain size increase with SEBS content. The phaseseparated thin film shows nano-domains at $10 \mathrm{wt} \%$ to microdomains at $25 \mathrm{wt} \%$. This suggests that the introduction of SEBS increases the phase separation of the blend. In comparison, the phase-separation in PCE10: $\mathrm{PC}_{71} \mathrm{BM}$ mixture is less noticeable than P3HT:PC ${ }_{61} \mathrm{BM}$ for the same content of SEBS (Fig. S13, $\mathrm{ESI} \dagger$ ). On the contrary, the topography indicates relatively good miscibility between SEBS and PCE10: PC $_{71} \mathrm{BM}$ blend.

Fig. 7d displays the normalized absorption spectra of PCE10: $\mathrm{PC}_{71} \mathrm{BM}$ thin film with SEBS at a weight ratio between 0 and $50 \mathrm{wt} \%$ relative to $\mathrm{PC}_{71} \mathrm{BM}$. All spectra were normalized at $486 \mathrm{~nm}$ corresponding to $\mathrm{PC}_{71} \mathrm{BM}$ peak. The addition of SEBS decreases the absorption intensity of PCE10 peaks at 645 and $708 \mathrm{~nm}$. SEBS does not absorb in the visible range; its addition leads to the dilution of PCE10 and $\mathrm{PC}_{71} \mathrm{BM}$, as expected.

To test the elastic modulus and stretchability of the $\mathrm{BHJ}$ films, thick films were made by the solution drop-casting of PCE10:PC ${ }_{71}$ BM:SEBS with $3 \%$ DIO on glass, annealed at $50{ }^{\circ} \mathrm{C}$ for two hours and washed for $30 \mathrm{~min}$ in a methanol bath to remove any residue of DIO co-solvent. While DIO induces a better morphology, ${ }^{66,68}$ it may act as a lubricant and decrease Young's modulus in some cases ${ }^{13,69}$ and increase the stiffness of polymers blend in others. ${ }^{70}$ The drying time is critical to avoid any contribution of the solvent and co-solvent to the mechanical properties. We measured the loss of mass under vacuum at $50{ }^{\circ} \mathrm{C}$, at a fixed time to make sure that the elasticity is not due to an excess of solvent in PCE10: $\mathrm{PC}_{71} \mathrm{BM}$ films (Fig. S14, ESI $\dagger$ ). Our observation suggests that thick PCE10: $\mathrm{PC}_{71} \mathrm{BM}$ film requires at least an hour of drying before the tensile test. After applying $90 \mathrm{~min}$ annealing under vacuum, stress-strain characteristics were recorded at a fixed weight percent of SEBS. The Young's modulus deduced by the slope at the origin of the stress-strain curve is plotted in Fig. 7e, and compared to the buckling method. The two techniques show similar values. At $0 \mathrm{wt} \%$ SEBS, the film displays an elastic modulus of around $350 \mathrm{MPa}$ compared to $450 \mathrm{MPa}$ by the buckling method. Our results are in accordance with the elastic modulus reported between $0.1-0.4 \mathrm{GPa}$ for neat PCE10. ${ }^{71}$ Elastic moduli decrease up to $60 \mathrm{MPa}$ by stress-strain and $77 \mathrm{MPa}$ by buckling with $50 \mathrm{wt} \%$ SEBS. This decrease represents between 80 to $85 \%$ reduction of initial Young's modulus. The buckling method leads to Young's modulus of the same order of magnitude compared to the stress-strain way. SEBS blending offers an excellent softening effect. The strain at break increases by 4 -fold with $50 \mathrm{wt} \%$ SEBS compared to the pristine, demonstrating an increase of the stretchability. These results are coherent compared to the previous study with P3HT:PC ${ }_{61} \mathrm{BM}$ in presence of SEBS.
Fig. 7f sows the evolution of the photovoltaic characteristics in function of SEBS content. The addition of SEBS demonstrates a decrease in the short circuit current density from 17.3 for the neat polymers blend $(1: 1.5)$ to $11.1 \mathrm{~mA} \mathrm{~cm}^{-2}$ for the mixture with $50 \mathrm{wt} \%$ SEBS. FF decreases less than $15 \%$ with $50 \mathrm{wt} \%$ SEBS compared to neat blend, while $V_{\text {oc }}$ remains unchanged. An overall decay of PCE is noticed. PCE drops more than $20 \%$ at $25 \mathrm{wt} \%$ SEBS and $45 \%$ at $50 \mathrm{wt} \%$ SEBS. This suggests that SEBS has the same effect on the efficiency of PCE10:PC ${ }_{71} \mathrm{BM}$ that, as previously seen with P3HT:PC ${ }_{61} \mathrm{BM}$.

With the recent development of the non-fullerene acceptors, the PCE has progressively increased by over $18 \% .^{72-75}$ Poly[ $[2,6-$ (4,8-bis(5-(2-ethylhexylthio)-4-fluorothiophen-2-yl)-benzo[1,2- $b$ : 4,5- $\left.b^{\prime}\right]$ dithiophene) $)$-alt-(5,5-(1',3'-di-2-thienyl-5', $7^{\prime}$-bis(2-ethylhexyl)benzo[ $\left.1^{\prime}, 2^{\prime}-c: 4^{\prime}, 5^{\prime}-c^{\prime}\right]$ dithiophene-4,8-dione)] (PCE13 or PBDB-T-SF) was blended with 3,9-bis(2-methylene-((3-(1,1-dicyanomethylene)-6,7-difluoro)-indanone))-5,5,11,11-tetrakis(4hexylphenyl)-dithieno[2,3- $\left.d: 2^{\prime}, 3^{\prime}-d^{\prime}\right]$-s-indaceno[1,2- $\left.b: 5,6-b^{\prime}\right] \mathrm{di}-$ thiophene (IT-4F). This produces PCE13:IT-4F blend, whose chemical structures are given in Fig. 8a. Fig. 8b displays the absorption spectra of the polymers. The low bandgap donor polymer (PCE13) exhibits an absorption peak onset at $684 \mathrm{~nm}$ corresponding to an optical band gap of $1.8 \mathrm{eV}$, while IT-4F acceptor presents at peak onset at $786 \mathrm{~nm}$. PCE13:IT-4F at a weight ratio of $1: 1$, covers the absorption spectra of the two component fully. The ITO/PEDOT:PSS/PCE13:IT-4F/DPO/Al solar cell demonstrates a power conversion efficiency of over $11 \%$, in accordance with the literature. ${ }^{63}$ Next, we investigate the mechanical and electrical properties of PCE13:IT-4F bulk heterojunction in the presence of SEBS.

PCE13, IT-4F, and SEBS were mixed in solution before deposition. The SEBS content is described as relative to IT-4F acceptor. The morphology of the thin film was characterized by optical microscopy (Fig. 8c). A micro-phase separation is noticed at $50 \mathrm{wt} \%$ SEBS. The absorption spectra in Fig. 8d confirmed the phase-separated morphology. The spectra were normalized to IT-4F (786 nm), and PCE13 peak intensity increases with the progressive introduction of SEBS.

The mechanical properties of PCE13:IT-4F blend have been determined by the buckling method and stress-strain technique in Fig. 8e. PCE13:IT-4F was deposited by spin coating on pre-strained PDMS rectangles using different spin speeds to achieve at least three thicknesses for the buckling method. Buckling wavelengths were obtained from the optical microscopy image, and a profilometer measured the thickness. In Fig. 8e, the Young's moduli are plotted in function of the concentration. The stress-strain method gives higher tensile modulus values, but the same behavior is observed compared to the buckling technique. With no SEBS elastomer, Young's modulus is about $310 \mathrm{MPa}$ by stress-strain or $220 \mathrm{MPa}$ by buckling method. This is a bit less than PCE10: $\mathrm{PC}_{71} \mathrm{BM}$. It decreases to $200 \mathrm{MPa}$ with $10 \mathrm{wt} \%$ SEBS, $115 \mathrm{MPa}$ for 25 wt\% SEBS, and $98 \mathrm{MPa}$ for $50 \mathrm{wt} \%$ SEBS by the stress-strain method. With the buckling method, the tensile modulus decreases up to $35 \mathrm{MPa}$ with $50 \mathrm{wt} \%$ SEBS. This suggests that again SEBS plays a crucial role in the mechanical properties. 

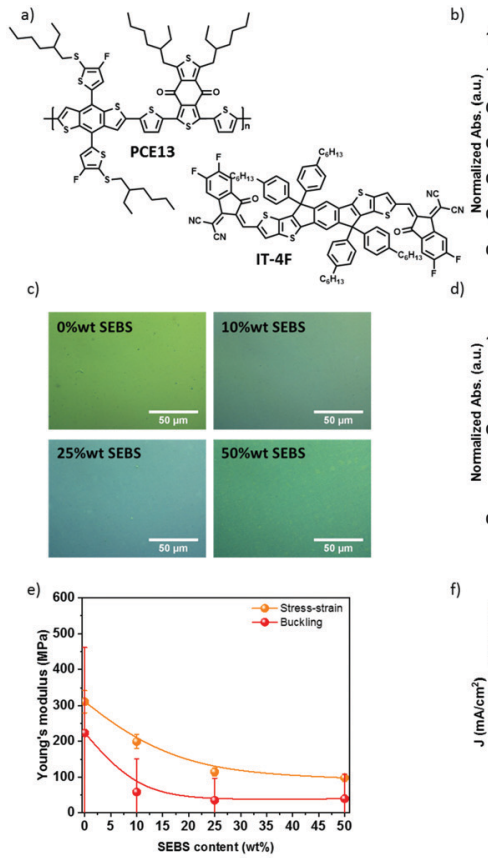

g)

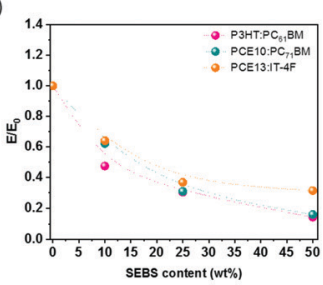

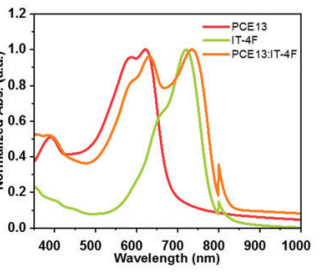

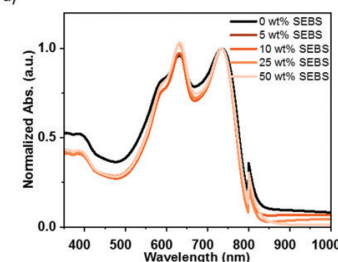

f)
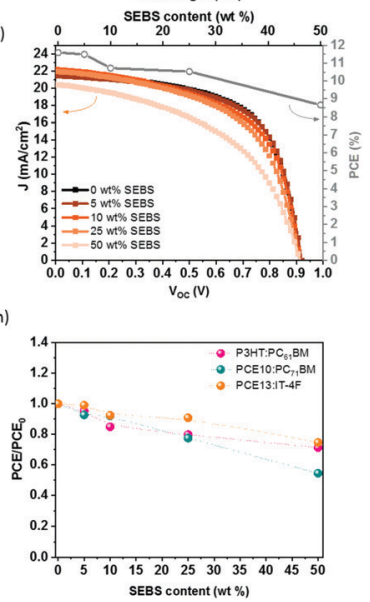

Fig. 8 (a) chemical structures of PCE13 and IT-4F. (b) UV-visible absorption spectra of PCE13, IT-4F, and PCE13:IT-4F (1:1) blend. (c) Optical morphology and (d) UV-visible absorption spectra of PCE13:IT-4F mixed with SEBS elastomer. (e) Determination of Young's moduli of PCE13:IT-4F with $0,10,25$, and $50 \mathrm{wt} \%$ SEBS by buckling method or by direct stressstrain measurements and (f) $J-V$ characteristics curves of PCE13:IT-4F with SEBS elastomer and the associated PCE. Comparative effect of SEBS on the $(\mathrm{g})$ initial elastic modulus and $(\mathrm{h})$ initial power conversion efficiency.

Fig. 8f illustrates the impact of SEBS on the photovoltaic performances of PCE13:IT-4F. For this system, $J_{\text {sc }}$ decreases slightly from 21.7 to $19.4 \mathrm{~mA} \mathrm{~cm}^{-2}$ with a SEBS content of 0 and $50 \mathrm{wt} \%$, respectively (Fig. 8f). $V_{\text {oc }}$ remains constant at $0.91 \mathrm{~V}$, and the fill factor decays from $58.8 \%$ at $0 \mathrm{wt} \%$ SEBS to $49 \%$ at 50 wt\% SEBS, which is more pronounced than for PCE10: $\mathrm{PC}_{71} \mathrm{BM}$. Overall, the average PCE decreases from 11.6 to $8.6 \%$, while $50 \mathrm{wt} \%$ is added, corresponding to a $25 \%$ loss of the initial PCE. At $25 \mathrm{wt} \%$ SEBS, PCE decreases only to $10.6 \%$, i.e. less than 10\% PCE loss. Fig. S17 (ESI $\dagger$ ) shows a decrease in EQE when SEBS is added to the blend. This result suggests that the addition of SEBS increases the charge losses by lowering the exciton dissociation yield or increasing the charge recombination. The decrease in the integrated EQE is consistent with the decrease in $J_{\text {sc }}$.

Fig. $8 \mathrm{~g}$ and $\mathrm{h}$ summarizes the effect of SEBS on Young's modulus and the PCE, depending on the studied BHJ. For all the acceptor:donor blends, the addition of SEBS as a ternary blend component improves the ductility of the film as

suggested by a decrease of the elastic modulus over $70 \%$ at $50 \mathrm{wt} \%$ SEBS, while PCE remains within 60\%. The introduction of SEBS is a versatile tool that can be adaptable to any $\mathrm{BHJ}$ system (providing that common solvent can be found), assuring good mechanical properties and a minimal loss of PCE. These results demonstrate the possibility of tailoring mechanical properties and photovoltaic performances. A concentration up to $25 \mathrm{wt} \%$ SEBS could be introduced into acceptor:donor blend with primarily tailored softness i.e., Young's modulus. Moreover, it seems that the chemical nature of SEBS is well adapted whatever the used acceptor (fullerene or non-fullerene) and donor. Until 25\% wt SEBS, miscibility has minor importance in PCE results. Indeed, the GIWAXS analysis of PCE10: $\mathrm{PC}_{71} \mathrm{BM}$ and PCE13:IT-4F in the presence of SEBS would reveal similar results to P3HT:PC ${ }_{61} \mathrm{BM}$. Furthermore, the crack-onset has to be studied to attest the ability to be stretched on PDMS. Besides the efficiency and the elasticity, nowadays the thermal stability remains an issue, and the addition of SEBS in acceptor:donor blend could be explored as a solution to limit the losses over time.

\section{Conclusions}

Different strategies have been used to improve the mechanical properties of the photoactive $\mathrm{BHJ}$ layer of organic photovoltaic devices to enable mechanically robust and stretchable devices. The addition of $\mathrm{C}_{12} \mathrm{~N}_{3}, \mathrm{PEG}_{3} \mathrm{~N}_{3}$, and SEBS into P3HT:PC ${ }_{61} \mathrm{BM}$ blend slows down the $\mathrm{PC}_{61} \mathrm{BM}$ diffusivity and crystallization, which are the source of degradation. Both elastomer blending and cross-linking strategies demonstrate a softening effect. However, the blending approach is shown to extend beyond fullerene-based solar cells to non-fullerene systems processed at low or room temperature. The alpha temperature decreases in the presence of the diazide cross-linker, suggesting that plasticization occurs and is responsible for the softening effect. In the case of elastomer addition, the softening seems more related to incorporating a soft rubber with low interaction with the photoactive components, which form an effective bulk heterojunction. While the elastomer blending leads to the softest films among both strategies studied, the cross-linking strategy appears to be better at not disturbing the BHJ phaseseparation, maintaining high photovoltaic performance in fullerene-based solar cells. Despite this advantage, the elastomer blending approach, thermoplastic elastomer such as using SEBS, provides a more versatile strategy to enhance the mechanical properties (e.g., Young's modulus) of a wide range of non-fullerene $\mathrm{BHJ}$ systems making it widely applicable to modern OPV systems. With the fast progress in OPV, this kind of method would easily find its place due to its low cost, high adaptability, and high mechanical compliance. Besides some engineering issues to build a fully stretchable solar cell that needs to be solved, our investigation demonstrates the efficiency of elastomer blending in P3HT:PC ${ }_{61} \mathrm{BM}, \mathrm{PCE} 10: \mathrm{PC}_{71} \mathrm{BM}$, and PCE13:IT-4F, all of which appear to retain their photoactive functionality in OPV devices despite significant loading of the 
elastomer. Although this result gives a possible route for inherently stretchable solar cells, more progress is needed on the multi-layer integration front to construct fully stretchable solar cell device stacks and modules.

\section{Conflicts of interest}

There are no conflicts to declare.

\section{Acknowledgements}

This publication is based upon work supported by the King Abdullah University of Science and Technology (KAUST) Office of Sponsored Research (OSR) under Award No. OSR-2018-CARF/ CCF-3079, and No. OSR-2019-CRG8-4095.3.

\section{Notes and references}

1 J. Wang, Z. Zheng, Y. Zu, Y. Wang, X. Liu, S. Zhang, M. Zhang and J. Hou, Adv. Mater., 2021, 2102787.

2 E. Dauzon, X. Sallenave, C. Plesse, F. Goubard, A. Amassian and T. D. Anthopoulos, Adv. Mater., 2021, 2101469.

3 F. C. Krebs, M. Biancardo, B. Winther-Jensen, H. Spanggard and J. Alstrup, Sol. Energy Mater. Sol. Cells, 2006, 90, 1058-1067.

4 M. Jørgensen, K. Norrman and F. C. Krebs, Sol. Energy Mater. Sol. Cells, 2008, 92, 686-714.

5 F. C. Krebs, T. D. Nielsen, J. Fyenbo, M. Wadstrøm and M. S. Pedersen, Energy Environ. Sci., 2010, 3, 512.

6 F. C. Krebs, S. A. Gevorgyan and J. Alstrup, J. Mater. Chem., 2009, 19, 5442.

7 M. Jørgensen, K. Norrman, S. A. Gevorgyan, T. Tromholt, B. Andreasen and F. C. Krebs, Adv. Mater., 2012, 24, 580-612.

8 W. R. Mateker and M. D. McGehee, Adv. Mater., 2017, 29, 1603940.

9 M. Karakawa, K. Suzuki, T. Kuwabara, T. Taima, K. Nagai, M. Nakano, T. Yamaguchi and K. Takahashi, Org. Electron., 2020, 76, 105448.

10 S. Savagatrup, A. D. Printz, T. F. O’Connor, A. V. Zaretski, D. Rodriquez, E. J. Sawyer, K. M. Rajan, R. I. Acosta, S. E. Root and D. J. Lipomi, Energy Environ. Sci., 2015, 8, 55-80.

11 A. D. Printz, S. Savagatrup, D. Rodriquez and D. J. Lipomi, Sol. Energy Mater. Sol. Cells, 2015, 134, 64-72.

12 D. J. Lipomi, H. Chong, M. Vosgueritchian, J. Mei and Z. Bao, Sol. Energy Mater. Sol. Cells, 2012, 107, 355-365.

13 S. Savagatrup, A. S. Makaram, D. J. Burke and D. J. Lipomi, Adv. Funct. Mater., 2014, 24, 1169-1181.

14 S. Savagatrup, A. D. Printz, D. Rodriquez and D. J. Lipomi, Macromolecules, 2014, 47, 1981-1992.

15 D. J. Lipomi, B. C.-K. C.-K. Tee, M. Vosgueritchian and Z. Bao, Adv. Mater., 2011, 23, 1771-1775.

16 Y.-T. Hsieh, J.-Y. Chen, C.-C. Shih, C.-C. Chueh and W.-C. Chen, Org. Electron., 2018, 53, 339-345.
17 N. El-Atab, N. Qaiser, R. Bahabry and M. M. Hussain, Adv. Energy Mater., 2019, 1902883, 1-7.

18 L. Derue, O. Dautel, A. Tournebize, M. Drees, H. Pan, S. Berthumeyrie, B. Pavageau, E. Cloutet, S. Chambon, L. Hirsch, A. Rivaton, P. Hudhomme, A. Facchetti and G. Wantz, Adv. Mater., 2014, 26, 5831-5838.

19 G. Wantz, L. Derue, O. Dautel, A. Rivaton, P. Hudhomme and C. Dagron-Lartigau, Polym. Int., 2014, 63, 1346-1361.

$20 \mathrm{~J}$. W. Rumer and I. McCulloch, Mater. Today, 2015, 18, 425-435.

21 G.-J. N. Wang, L. Shaw, J. Xu, T. Kurosawa, B. C. Schroeder, J. Y. Oh, S. J. Benight and Z. Bao, Adv. Funct. Mater., 2016, 26, 7254-7262.

22 J. Y. Oh, S. Rondeau-Gagné, Y.-C. Chiu, A. Chortos, F. Lissel, G.-J. N. Wang, B. C. Schroeder, T. Kurosawa, J. Lopez, T. Katsumata, J. Xu, C. Zhu, X. Gu, W.-G. Bae, Y. Kim, L. Jin, J. W. Chung, J. B.-H. Tok and Z. Bao, Nature, 2016, 539, 411-415.

23 G.-J. N. Wang, Y. Zheng, S. Zhang, J. Kang, H.-C. Wu, A. Gasperini, H. Zhang, X. Gu and Z. Bao, Chem. Mater., 2019, 31, 6465-6475.

24 A. D. Printz, S. Savagatrup, D. J. Burke, T. N. Purdy and D. J. Lipomi, RSC Adv., 2014, 4, 13635-13643.

25 F. Sugiyama, A. T. Kleinschmidt, L. V. Kayser, D. Rodriquez, M. Finn, M. A. Alkhadra, J. M.-H. Wan, J. Ramírez, A. S.C. Chiang, S. E. Root, S. Savagatrup and D. J. Lipomi, Polym. Chem., 2018, 9, 4354-4363.

26 M. T. Dang, L. Hirsch, G. Wantz and J. D. Wuest, Chem. Rev., 2013, 113, 3734-3765.

27 E. Song, B. Kang, H. H. Choi, D. H. Sin, H. Lee, W. H. Lee and K. Cho, Adv. Electron. Mater., 2016, 2, 1-8.

28 G. Zhang, M. McBride, N. Persson, S. Lee, T. J. Dunn, M. F. Toney, Z. Yuan, Y. H. Kwon, P. H. Chu, B. Risteen and E. Reichmanis, Chem. Mater., 2017, 29, 7645-7652.

29 D. Choi, H. Kim, N. Persson, P. H. Chu, M. Chang, J. H. Kang, S. Graham and E. Reichmanis, Chem. Mater., 2016, 28, 1196-1204.

30 M. Shin, J. Y. Oh, K.-E. Byun, Y.-J. Lee, B. Kim, H.-K. Baik, J.-J. Park and U. Jeong, Adv. Mater., 2015, 27, 1255-1261.

31 J. W. Mok, Z. Hu, C. Sun, I. Barth, R. Muñoz, J. Jackson, T. Terlier, K. G. Yager and R. Verduzco, Chem. Mater., 2018, 30, 8314-8321.

32 S. Chen, S. Jung, H. J. Cho, N.-H. Kim, S. Jung, J. Xu, J. Oh, Y. Cho, H. Kim, B. Lee, Y. An, C. Zhang, M. Xiao, H. Ki, Z.G. Zhang, J.-Y. Kim, Y. Li, H. Park and C. Yang, Angew. Chem., Int. Ed., 2018, 57, 13277-13282.

33 J. T. Seitz, J. Appl. Polym. Sci., 1993, 49, 1331-1351.

34 F. P. V. Koch, J. Rivnay, S. Foster, C. Müller, J. M. Downing, E. Buchaca-Domingo, P. Westacott, L. Yu, M. Yuan, M. Baklar, Z. Fei, C. Luscombe, M. A. McLachlan, M. Heeney, G. Rumbles, C. Silva, A. Salleo, J. Nelson, P. Smith and N. Stingelin, Prog. Polym. Sci., 2013, 38, 1978-1989.

35 D. Rodriquez, J.-H. Kim, S. E. Root, Z. Fei, P. Boufflet, M. Heeney, T.-S. Kim and D. J. Lipomi, ACS Appl. Mater. Interfaces, 2017, 9, 8855-8862.

36 M. Selivanova, S. Zhang, B. Billet, A. Malik, N. Prine, E. Landry, X. Gu, P. Xiang and S. Rondeau-Gagné, Macromolecules, 2019, 52, 7870-7877. 
37 J. Xu, S. Wang, G.-J. N. Wang, C. Zhu, S. Luo, L. Jin, X. Gu, S. Chen, V. R. Feig, J. W. F. To, S. Rondeau-Gagné, J. Park, B. C. Schroeder, C. Lu, J. Y. Oh, Y. Wang, Y.-H. Kim, H. Yan, R. Sinclair, D. Zhou, G. Xue, B. Murmann, C. Linder, W. Cai, J. B.-H. Tok, J. W. Chung and Z. Bao, Science, 2017, 355, 59-64.

38 C. M. Stafford, C. Harrison, K. L. Beers, A. Karim, E. J. Amis, M. R. VanLandingham, H.-C. Kim, W. Volksen, R. D. Miller and E. E. Simonyi, Nat. Mater., 2004, 3, 545-550.

39 N. Bowden, S. Brittain, A. G. Evans, J. W. Hutchinson and G. Whitesides, Nature, 1998, 393, 146-149.

40 V. Koncar, Smart Textiles for In Situ Monitoring of Composites, Elsevier, 2019, pp. 295-381.

41 D. Tahk, H. H. Lee and D.-Y. Khang, Macromolecules, 2009, 42, 7079-7083.

42 Z. Jiang, J. Appl. Crystallogr., 2015, 48, 917-926.

43 M. Prato, Q. C. Li, F. Wudl and V. Lucchini, J. Am. Chem. Soc., 1993, 115, 1148-1150.

44 E. F. V. Scriven and K. Turnbull, Chem. Rev., 1988, 88, 297-368.

45 J. C. Hummelen, B. W. Knight, F. LePeq, F. Wudl, J. Yao and C. L. Wilkins, J. Org. Chem., 1995, 60, 532-538.

46 M. Jørgensen, K. Norrman and F. C. Krebs, Sol. Energy Mater. Sol. Cells, 2008, 92, 686-714.

47 A. Swinnen, I. Haeldermans, M. vande Ven, J. D’Haen, G. Vanhoyland, S. Aresu, M. D'Olieslaeger and J. Manca, Adv. Funct. Mater., 2006, 16, 760-765.

48 M. Campoy-Quiles, T. Ferenczi, T. Agostinelli, P. G. Etchegoin, Y. Kim, T. D. Anthopoulos, P. N. Stavrinou, D. D. C. Bradley and J. Nelson, Nat. Mater., 2008, 7, 158-164.

49 B. O’Connor, E. P. Chan, C. Chan, B. R. Conrad, L. J. Richter, R. J. Kline, M. Heeney, I. McCulloch, C. L. Soles and D. M. DeLongchamp, ACS Nano, 2010, 4, 7538-7544.

50 J.-S. Kim, J.-H. Kim, W. Lee, H. Yu, H. J. Kim, I. Song, M. Shin, J. H. Oh, U. Jeong, T.-S. Kim and B. J. Kim, Macromolecules, 2015, 48, 4339-4346.

51 B. J. Kim, Y. Miyamoto, B. Ma and J. M. J. Fréchet, Adv. Funct. Mater., 2009, 19, 2273-2281.

52 H. Sirringhaus, P. J. Brown, R. H. Friend, M. M. Nielsen, K. Bechgaard, B. M. W. Langeveld-Voss, A. J. H. Spiering, R. A. J. Janssen, E. W. Meijer, P. Herwig and D. M. de Leeuw, Nature, 1999, 401, 685-688.

53 N. Kiriy, E. Jähne, H.-J. Adler, M. Schneider, A. Kiriy, G. Gorodyska, S. Minko, D. Jehnichen, P. Simon, A. A. Fokin and M. Stamm, Nano Lett., 2003, 3, 707-712.

54 P. Müller-Buschbaum, Adv. Mater., 2014, 26, 7692-7709.

55 Y.-C. Huang, C.-S. Tsao, C.-M. Chuang, C.-H. Lee, F.-H. Hsu, H.-C. Cha, C.-Y. Chen, T.-H. Lin, C.-J. Su, U.-S. Jeng and W.-F. Su, J. Phys. Chem. C, 2012, 116, 10238-10244.

56 N. D. Treat, M. A. Brady, G. Smith, M. F. Toney, E. J. Kramer, C. J. Hawker and M. L. Chabinyc, Adv. Energy Mater., 2011, 1, 82-89.

57 B. Schmidt-Hansberg, M. Sanyal, M. F. G. Klein, M. Pfaff, N. Schnabel, S. Jaiser, A. Vorobiev, E. Müller, A. Colsmann, P. Scharfer, D. Gerthsen, U. Lemmer, E. Barrena and W. Schabel, ACS Nano, 2011, 5, 8579-8590.
58 J. Rivnay, S. C. B. Mannsfeld, C. E. Miller, A. Salleo and M. F. Toney, Chem. Rev., 2012, 112, 5488-5519.

59 T. T. Ngo, D. N. Nguyen and V. T. Nguyen, Adv. Nat. Sci.: Nanosci. Nanotechnol., 2012, 3, 045001.

60 J. Zhao, A. Swinnen, G. Van Assche, J. Manca, D. Vanderzande and B. Van Mele, J. Phys. Chem. B, 2009, 113, 1587-1591.

61 J. Zhao, A. Swinnen, G. Van Assche, J. Manca, D. Vanderzande and B. Van Mele, J. Phys. Chem. B, 2009, 113, 1587-1591.

62 A. Rudin and P. Choi, The Elements of Polymer Science \& Engineering, Elsevier, 2013, pp. 231-274.

63 Y. Lin, B. Adilbekova, Y. Firdaus, E. Yengel, H. Faber, M. Sajjad, X. Zheng, E. Yarali, A. Seitkhan, O. M. Bakr, A. El-Labban, U. Schwingenschlögl, V. Tung, I. McCulloch, F. Laquai and T. D. Anthopoulos, Adv. Mater., 2019, 31, 1902965.

64 Z. Liu, Y. Gao, J. Dong, M. Yang, M. Liu, Y. Zhang, J. Wen, H. Ma, X. Gao, W. Chen and M. Shao, J. Phys. Chem. Lett., 2018, 9, 6955-6962.

65 L. K. Jagadamma, H. Hu, T. Kim, G. O. N. Ndjawa, A. E. Mansour, A. El Labban, J. C. D. Faria, R. Munir, D. H. Anjum, M. A. McLachlan and A. Amassian, Nano Energy, 2016, 28, 277-287.

66 L. Song, W. Wang, E. Barabino, D. Yang, V. Körstgens, P. Zhang, S. V. Roth and P. Müller-Buschbaum, ACS Appl. Mater. Interfaces, 2019, 11, 3125-3135.

67 Z. He, B. Xiao, F. Liu, H. Wu, Y. Yang, S. Xiao, C. Wang, T. P. Russell and Y. Cao, Nat. Photonics, 2015, 9, 174-179.

68 J. J. van Franeker, M. Turbiez, W. Li, M. M. Wienk and R. A. J. Janssen, Nat. Commun., 2015, 6, 6229.

69 L. Li, J. Liang, H. Gao, Y. Li, X. Niu, X. Zhu, Y. Xiong and Q. Pei, ACS Appl. Mater. Interfaces, 2017, 9, 40523-40532.

70 J.-H. Kim, J. Noh, H. Choi, J.-Y. Lee and T.-S. Kim, Chem. Mater., 2017, 29, 3954-3961.

71 N. Balar and B. T. O'connor, Macromolecules, 2017, 50, 8611-8618.

72 Y. Lin, Y. Firdaus, F. H. Isikgor, M. I. Nugraha, E. Yengel, G. T. Harrison, R. Hallani, A. El-Labban, H. Faber, C. Ma, X. Zheng, A. Subbiah, C. T. Howells, O. M. Bakr, I. McCulloch, S. De Wolf, L. Tsetseris and T. D. Anthopoulos, ACS Energy Lett., 2020, 5, 2935-2944.

73 Q. Liu, Y. Jiang, K. Jin, J. Qin, J. Xu, W. Li, J. Xiong, J. Liu, Z. Xiao, K. Sun, S. Yang, X. Zhang and L. Ding, Sci. Bull., 2020, 65, 272-275.

74 Y. Lin, M. I. Nugraha, Y. Firdaus, A. D. Scaccabarozzi, F. Aniés, A.-H. Emwas, E. Yengel, X. Zheng, J. Liu, W. Wahyudi, E. Yarali, H. Faber, O. M. Bakr, L. Tsetseris, M. Heeney and T. D. Anthopoulos, ACS Energy Lett., 2020, 5, 3663-3671.

75 Y. Lin, A. Magomedov, Y. Firdaus, D. Kaltsas, A. El-Labban, H. Faber, D. R. Naphade, E. Yengel, X. Zheng, E. Yarali, N. Chaturvedi, K. Loganathan, D. Gkeka, S. H. AlShammari, O. M. Bakr, F. Laquai, L. Tsetseris, V. Getautis and T. D. Anthopoulos, ChemSusChem, 2021, 14(17), 3569-3578. 